\section{Characterisation of yeasts isolated from 'Nduja of Spilinga}

\author{
Filippo Giarratana, Daniele Muscolino, \\ Chiara Beninati, Alessandro Giuffrida, \\ Graziella Ziino, Antonio Panebianco \\ Dipartimento di Scienze Veterinarie, \\ Università degli Studi di Messina, Italy
}

\section{Abstract}

The 'Nduja of Spilinga protected geographical indication (PGI) is a spreadable italian salami, obtained by using fat (50\%), lean of pork (25\%), chili pepper (25\%) and $\mathrm{NaCl}$, stuffed into natural pork casing. Its predominant flora is represented by yeasts, reaching at the end of seasoning values of $6 \log \mathrm{CFU} / \mathrm{g}$. Considering the need to enhance and protect traditional local products, it seemed interesting to carry out a characterisation of yeasts of the 'Nduja of Spilinga PGI. A total of 127 strains of yeast isolated from samples of 'Nduja of Spilinga PGI (79 strains from samples at different days of curing and 48 from samples of commerce) was subjected to morphological identification, hydrolysis of urea, lipolytic activity and identification with API 20C AUX, ID $32 \mathrm{C}$ and simplified identification systems. One hundred twenty three (96.8\%) strains were attributable to the phylum Ascomycetes (urease-negative), the remaining 4 strains (3.2\%) were Basidiomycetes (urease-positive). Debaryomyces hansenii and its anamorph shape, Candida famata, represented the most prevalent species (61.42 and $17.32 \%$ respectively), followed by Candida glabrata (8.66\%), Pichia (Candida) guilliermondii (5.17\%), Candida parapsilosis and Rhodotorula glutinis (1.57\%). Candida catenulata Criptococcus uniguttulatus, Rhodotorula minuta, Candida zeylanoides and Candida utilis were observed with $0.79 \%$. The lipolytic activity was observed only in 10 strains of $D$. hansenii and in one of $C$. zeylanoides. Further investigation will contribute to the selection of indigenous strains that could be used for the creation of specific starter, useful to improve the process of characterisation of the 'Nduja of Spilinga and also to guarantee its safety.

\section{Introduction}

The 'Nduja of Spilinga protected geographical indication (PGI) is a spreadable salami produced in Calabria region (Southern Italy), on the plateau of Monte Poro. It is produced espe- cially in a little town called Spilinga (Vibo Valencia province), from which its name is derived.

It is obtained using only lean and fat of pork, red pepper and sodium chloride. The lean and fat used is derived from lard, bacon, cheek lard and throat, trimming of lean, obtained exclusively from pigs slaughtered in Italy. The mixture is made by using $50 \%$ fat, $25 \%$ lean meat and the remaining $25 \%$ red pepper (sweet and spicy) dried and shredded. The red pepper, according to the product specification, must be exclusively produced in Calabria region. After trituration, $3 \% \mathrm{NaCl}$ is added to the mixture. Then it is stored at refrigeration temperature for $12 \mathrm{~h}$, followed by stuffing into natural casings (large intestine or caecum of pig) (Giuffrida and Callipo, 2010). The process continues with a phase of draining and drying at controlled temperature and humidity, and finally ripening, characterised by intense phenomena of proteolysis and lipolysis. Lipolysis is related to a relevant mycotic flora, predominantly represented by yeasts, which are characterised by lipolytic activity (Sorensen, 1997). In 'Nduja, the yeast at the end of seasoning reach values slightly below 6 log colony forming units $(\mathrm{CFU}) / \mathrm{g}$, representing the predominant flora (Giarratana et al., 2011), contrary to other Italian cured sausages (Comi and Cantoni,1980), which are characterised by value of $3 \log \mathrm{CFU} / \mathrm{g}$. Due the need to enhance and protect the traditional local products, it seemed interesting to carry out a characterisation of yeasts isolated from the 'Nduja of Spilinga PGI.

\section{Materials and Methods}

The present study was carried out on a total of 127 strains of yeast isolated from samples of 'Nduja of Spilinga PGI. Seventy-nine strains were from 15 samples analysed in a previous study (Giarratana et al., 2011) at different days of curing, while the remaining 48 strains were isolated from 15 'Nduja of Spilinga PGI collected at detail.

Twenty-five grams of each sample were collected and transferred into a sterile stomacher bag, where $225 \mathrm{~mL}$ of saline-peptone water was added in a ratio of 1:10, and then the mix were homogenised, for $120 \mathrm{~s}$ at $230 \mathrm{rpm}$, with a stomacher (Stomacher® 400 Circulator; International PBI s.p.a., Milan, Italy). Serial dilutions were made, and each dilution was inoculated in duplicate on plates of Dichloran Rose Bengal Chloramphenicol Agar (DRBC) (Oxoid Ltd., Basingstoke, UK) and of Malt Extract Agar (MEA) (Oxoid) and incubated at $25^{\circ} \mathrm{C}$ for 3-5 days. For each sample, colonies with different colours and morphology were selected. Single pure colonies obtained on
Correspondence: Filippo Giarratana, Dipartimento di Scienze Veterinarie, Università degli Studi di Messina, 98100 Messina (ME), Italy. Tel. +39.90 .3503768 - Fax: +39.90 .3503937 .

E-mail: fgiarratana@unime.it

Key words: Yeasts, 'Nduja of Spilinga, Salami, Debaryomyces hansenii.

Contributions: the authors contributed equally.

Conflict of interests: the authors declare no potential conflict of interests.

Received for publication: 12 May 2013. Revision received: 14 October 2013. Accepted for publication: 15 October 2013.

This work is licensed under a Creative Commons Attribution 3.0 License (by-nc 3.0)

(C) Copyright F. Giarratana et al., 2014 Licensee PAGEPress, Italy

Italian Journal of Food Safety 2014; 3:1694 doi:10.4081/ijfs.2014.1694

MEA, were subject to the following evaluation: i) morphological characterisation [colony morphology on MEA, cellular morphology by scanning electron microscope (SEM) (Phenom G2 ProX), and ascospores production on modified Gorodkowa agar were evaluated]; ii) hydrolysis of urea (streaking on Christensen's urea agar incubated at $25^{\circ} \mathrm{C}$ for 2 days, and on Rapid urea broth, at $37^{\circ} \mathrm{C}$ for $4 \mathrm{~h}$ ); iii) lipolytic activity [assayed by measuring the halo all around the colonies grown on butter agar at $25^{\circ} \mathrm{C}$ for 7 days. Butter-agar was prepared with yeast extract $(10 \mathrm{~g} / \mathrm{L})$, peptone $(10 \mathrm{~g} / \mathrm{L}), \mathrm{NaCl}(5 \mathrm{~g} / \mathrm{L})$, bacteriological agar $(15 \mathrm{~g} / \mathrm{L})$ in distilled water and the $\mathrm{pH}$ was adjusted to 7 and sterilised at $121^{\circ} \mathrm{C}$ for $15 \mathrm{~min}$. Successively, butter fat previously melted at $50^{\circ} \mathrm{C}$ and pasteurised $\left(100^{\circ} \mathrm{C}\right.$ for $5 \mathrm{~min}$ ) was added to the media with a concentration of $5 \%$.

All the strains were finally identified with API 20C AUX, ID 32C systems (bioMérieux, Marci L'Etoile, France) and with simplified identification system (Deák and Beuchat, 1996).

\section{Results}

One hundred twenty-three (96.8\%) strains isolated on MEA, appeared as spherical whitish colonies, raised, with a shiny surface. Microscopically cells were spherical or slightly oval, organised as single, in pairs or in short chains. No pseudomycelia was observed. These strains were ascribable to phylum Ascomycetes, resulting also urease negative.

The remaining 4 strains (3.2\%), instead, belonged to the phylum of Basidiomycetes, 
being urease positive. In particular, 3 strains (Rhodotorula spp.) were characterised by a typical pinky color on MEA, and the remaining (Criptococcus spp.) appeared translucent. In all cases the cells showed elliptical shaped, single or in pairs and no ascospores were observed.

Among the 127 isolates, Debaryomyces hansenii and its anamorfa shape, Candida famata, represented the most prevalent species, reaching values of 61.42 and $17.32 \%$ respectively, followed by Candida glabrata (8.66\%) and Pichia (Candida) guilliermondii (5.17\%) (Table 1). All the strains of Candida zeylanoides and 10 (7.8\%) of Debaryomyces hansenii showed lipolytic activity. The yeasts isolated from samples of commerce had charges of $6 \pm 0.3 \log \mathrm{CFU} / \mathrm{g}$. Figures 1 and 2 show the identifications of the strains isolated from the samples during the production and from commerce. In both type of samples, the species isolated with greater frequency were represented by Debaryomyces hansenii and its anamorfa shape, Candida famata. Higher values were observed in the samples during the production (Figure 1). Eleven strains (22.92\%) of Candida glabrata were isolated from samples of commerce (Figure 2).

\section{Discussion}

The yeasts identified in 'Nduja of Spilinga are similar to those reported in Italian and European meat products. The main species isolated in this study was $D$. hansenii with a prevalence of $84 \%$. D. hansenii is also frequently isolated from different Italian, Spanish and Danish meat products (Cocolin et al., 2006; Gardini et al., 2001; Nielsen et al., 2008; Nunez et al., 1996; Simoncini et al., 2007). In this regard $D$. hansenii was identified in $52 \%$ of the strains isolates from typical Lucan sausages (Gardini et al., 2001). A slightly lower prevalence (30\%) of D. hansenii was reported in Parma ham, followed by $C$. zeylanoides (23\%) and Debaryomyces maramus (21\%) (Simoncini et al., 2007). Candida famata, $C$. catenulata, $C$. guilliermondii, Hyphopichia burtonii, Yarrowia spp., Rhodotorula spp. and Cryptococcus spp. were instead occasionally found (Andrade et al., 2006; Simoncini et al., 2007).

D. hansenii is a yeast with $\mathrm{NaCl}$ tolerance (up to concentrations of $24 \%$ ), characterised by a very rapid aerobic metabolism. It is frequently isolated in cheeses, refrigerated foods, from brines for the production of cheese or meat products. It is able to metabolise lactic acid and citric acid and seems to have a good lipolytic and proteolytic activity. The lipolytic activity is performed not only by $D$. hansenii, but also by Candida zeylanoides, as observed in strains isolated from 'Nduja of Spilinga.

Further investigation must be carried out on lipolytic activity of yeast isolated from 'Nduja of Spilinga, due that it is made by $50 \%$ of fat. These studies, supported by the use of molecular techniques, could significantly contribute to improve the aroma and taste of this product.

\section{Conclusions}

Yeasts and moulds traditionally play, in fact, an important role in sausage fermentation and contribute to the formation of characteristic flavours and the surface appearance. In this regard the yeasts, notably Debaryomyces hansenii, contribute to nitrate reduction and colour formation (Grazia et al., 1989; Lucke and Heckelmann, 1987), and seem to influence
Table 1. Identification and percentage of isolated strains.

\begin{tabular}{|c|c|}
\hline Identification & $\begin{array}{c}\text { N. strains } \\
\text { isolated }(\%)\end{array}$ \\
\hline Debaryomyces hansenii & $78(61.42)$ \\
\hline Candida famata & $22(17.32)$ \\
\hline Candida glabrata & $11(8.66)$ \\
\hline Pichia (Candida) guilliermondi & $7(5.51)$ \\
\hline Candida parapsilosis & $2(1.57)$ \\
\hline Rhodotorula glutinis & $2(1.57)$ \\
\hline Candida catenulata & $1(0.79)$ \\
\hline Criptococcus uniguttulatus & $1(0.79)$ \\
\hline Rhodotorula minuta & $1(0.79)$ \\
\hline Candida zeylanoides & $1(0.79)$ \\
\hline Candida utilis & $1(0.79)$ \\
\hline
\end{tabular}

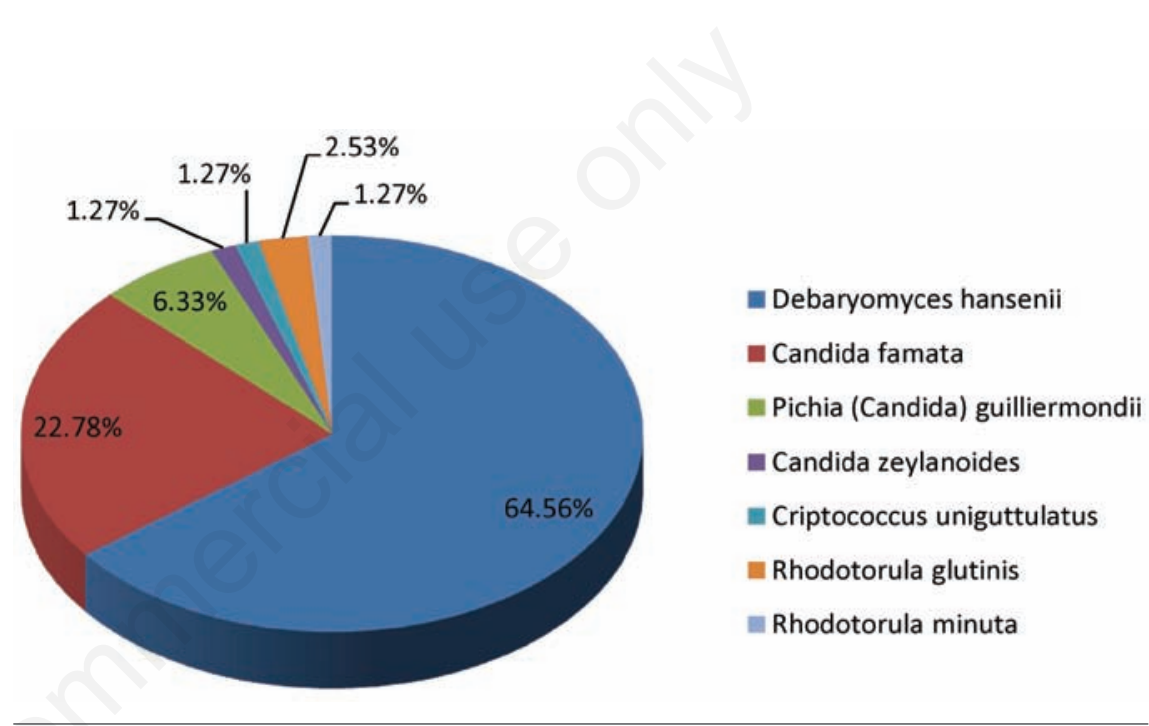

Figure 1. Identification and percentage of 79 strains isolated from samples during production.

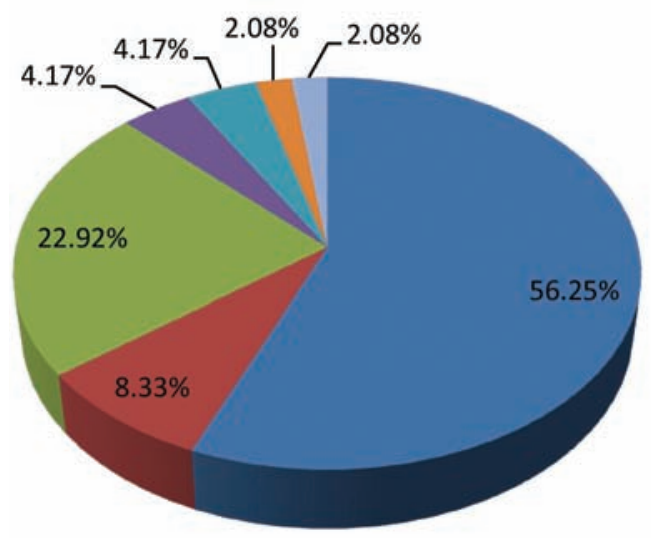

- Debaryomyces hansenii

- Candida famata

Candida glabrata

- Pichia (Candida)

guilliermondii

E Candida parapsilosis

- Candida utilis

Candida catenulata

Figure 2. Identification and percentage of 48 strains isolated from samples of commerce. 
the aromatic profile by an appreciable production of volatile esters (Sorensen, 1997). The eventual selection of autochthonous strains that could be used for the creation of specific starter, certainly could contribute to an improvement of the process of characterisation of 'Nduja of Spilinga, but also to guarantee a greater safety of the product. Several yeasts show, in fact, competitive action against different pathogens or spoilage bacteria, such as Enterobacteriaceae, as well as against moulds producing mycotoxins (Mbadi et al., 2004).

\section{References}

Andrade MJ, Rodriguez M, Sanchez B, Aranda E, Cordoba JJ, 2006. DNA typing methods for differentiation of yeasts related to drycured meat products. Int J Food Microbiol 107:48-58.

Cocolin L, Urso R, Rantsiou K, Cantoni C, Comi G, 2006. Dynamics and characterization of yeasts during natural fermenta- tion of Italian sausages. FEMS Yeast Res 6:692-701.

Comi G, Cantoni C, 1980. [I lieviti in insaccati crudi stagionati]. [Article in Italian]. Ind Aliment-Italy 19:857-60.

Deák T, Beuchat LR, 1996. Handbook of food spoilage yeasts. CRC Press, Boca Raton, FL, USA.

Gardini F, Suzzi G, Lombardi A, Galgano F, Crudele M, Andrighetto C, Schirone M, Tofalo R, 2001. A survey of yeasts in traditional sausages of southern Italy. FEMS Yeast Res 1:161-7.

Giarratana F, Marra A, Callipo E, Ziino G, Signorino D, Giuffrida A, Panebianco A, 2011. [Valutazioni igieniche e comportamento di Listeria monocytogenes nel corso della produzione della 'Nduja di Spilinga]. [Article in Italian]. Rivista AIVI 1:55-9.

Giuffrida A, Callipo E, 2010. [La 'Nduja: aspetti igienico-sanitari ed ispettivi]. In: Pugliese A, ed. ['Nduja: antropologia, storia, tecnologia di un salume calabrese]. [Book in Italian]. Armando siciliano ed., Messina.

Grazia L, Suzzi G, Romano P, Giudici P, 1989.
The yeasts of meat products.Yeast 5:495-9. Lucke FK, Heckelmann H, 1987. Starter cultures for dry sausages and raw ham composition and effect. Fleischwirtschaft 67:307-14.

Mbandi E, Brywig M, Shelef LA, 2004. Antilisterial effects of free fatty acids and monolaurin in beef emulsions and hot dogs. Food Microbiol 21:815-8.

Nielsen DS, Jacobsen T, Jespersen L, Koch AG, Arneborg N, 2008. Occurrence and growth of yeasts in processed meat productsimplications for potential spoilage. Meat Sci 80:919-26.

Nunez F, Rodriguez MM, Cordoba JJ, Bermudez ME, Asensio MA, 1996. Yeast population during ripening of dry-cured Iberian ham. Int J Food Microbiol 29:271-80.

Simoncini N, Rotelli D, Virgili R, Quintavalla S, 2007. Dynamics and characterization of yeasts during ripening of typical Italian dry-cured ham. Food Microbiol 24:577-84.

Sorensen BB, 1997. Lipolysis of pork fat by the meat starter culture Debaryomyces hansenii at various environmental conditions. Int J Food Microbiol 34:187-93. 